\title{
Age relative height, weight and body mass index percentiles of children in Jos, North-Central Nigeria
}

\author{
Ovayoza O. Mosugu', Francis Shinku², Jacob C. Nyam ${ }^{3}$, Emmanuel S. Mador ${ }^{4}$ \\ 1,2,3 Lecturer I, ${ }^{4}$ Professor, Department of Human Anatomy, Faculty of Basic Medical Sciences, University of Jos
}

Background: Interpretation of body mass index in children is quite different from that in adults which use standard weight status categories that are the same for all ages and for both men and women. Aims and Objective: The study was aimed at determining the prevalence of childhood obesity in Jos. Materials and Methods: A total of 371 children were enrolled in the study. Weight was taken with only light clothing and without foot wears. Height obtained without head-gears or shoes and the measuring flat tops pressed down to avoid errors due to tall hair. Body mass index were calculated for each subject as ratio of body weight to body height. All data were analyzed statistically and separately for different ages and the mean values for height against age, weight against age, height against weight and $\mathrm{BMI}$ for age was obtained with centiles of absolute deviations from the mean. Results: The age of the studied population ranged from $3-14$ years with mean of $8.4 \pm 2.8$. Height of the children on the other hand ranged from $0.9-1.64$ meters with mean value of 1.26 \pm 0.15 and their weight ranged from $10-76 \mathrm{~kg}$ with mean value of $25.6 \pm 9.2$. Out of the 371 children studied, $14(3.8 \%)$ were found to be underweight, $302(81.4 \%)$ had healthy weight while $41(11 \%)$ were at risk of overweight and $14(3.8 \%)$ were overweight. In addition, the body mass index of girls was found to be significantly higher than those of boys at 12 and 13 years only. Conclusion: It is concluded that the prevalence of childhood obesity is high in Jos, North-central Nigeria.

Keywords: Height; Weight; Children; Underweight; Overweight

\section{Access this article online}

Website:

http://nepjol.info/index.php/AJMS DOI: 10.3126/ajms.v12i8.36894

E-ISSN: 2091-0576 P-ISSN: 2467-9100

Copyright (c) 2021 Asian Journal of Medical Sciences

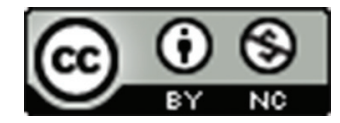

This work is licensed under a Creative Commons Attribution-NonCommercial 4.0 International License.

\section{INTRODUCTION}

Several investigators have studied weight in relation to height in Nigerian children ${ }^{1-6}$ but none of them has been able to provided body mass index (BMI) - for - age specific percentiles that can be used to interpret the meaning of BMI number for children and teenagers in our environment. Internationally, the standard for assessing body size in adults is body mass index. In adults that are 20 years old and above, their body mass index is interpreted using standard weight status categories that are the same for all ages and for both men and women while that of children is quite different. The principle used to interpret the meaning of BMI number for children and teenagers is that BMI - for - age percentile less than $5^{\text {th }}$ percentile means underweight while that from $5^{\text {th }}-$ $84^{\text {th }}$ percentiles means healthy weight and BMI - for - age percentiles from $85^{\text {th }}-94^{\text {th }}$ means risk of overweight. A child that has BMI - for - age percentile above $95^{\text {th }}$ is said to be overweight. The present study was designed to determine the prevalence of childhood obesity using BMI - for - age percentile for children in Jos, North-Central Nigeria. For children and teenagers, BMI - for - age specific percentiles are used for two reasons. The first reason is that the amount of body fat changes with age and the second reason is that the amount of body fat differs between girls and boys.

\section{MATERIALS AND METHODS}

This was a cross-sectional study carried out in Jos, North-Central Nigeria. Weight and height measurements 
were taken from children aged 3 - 14 years selected from randomly chosen nursery/primary schools in Jos metropolis without respect to socioeconomic status. The minimum sample size for the study was determined using the Cochran formula ${ }^{7}$ for simple proportion. $\mathrm{n}=\mathrm{z}^{2} \mathrm{pq} /$ $\mathrm{d}^{2}$ where $\mathrm{p}=11.4 \%$ (proportion of overweight Nigerian children in a study carried out in Uyo, Nigeria. ${ }^{8}$ The calculated minimum sample size was 155 . For the purpose of this study 371 school children were recruited. Children with gross disabilities were excluded from the study. Values for children under 5 years were obtained from children in play class. All observations were obtained by a single observer in order to eliminate observer-related errors. Before enrolling the children in the study, informed consent was obtained. Subjects were weighed after evacuating their bladder. They were weighed using weighing scale ZT-180A with only light clothing and without foot wears. Height values were obtained without head-gears or shoes and the measuring flat tops of the measuring instrument was pressed down as far as it can be made to avoid errors due to tall hair. Parallax was also avoided in the visual read-outs of the heights. Body mass index were calculated for each subject as ratio of body weight $(\mathrm{kg})$ to body height $\left(\mathrm{m}^{2}\right)$. Number cruncher statistical system (NCSS/97) was used to analyze the data. All data were analyzed statistically and separately for different ages and the mean values for height against age, weight against age, height against weight and BMI for age was obtained with standard errors of mean and centiles of absolute deviations from the mean derived from standard deviation values $\left(5^{\text {th }}, 15^{\text {th }}, 50^{\text {th }}, 85^{\text {th }}\right.$, and $95^{\text {th }}$ centiles). Differences between parameters compared were considered to be statistically significant within $95 \%$ confidence interval, a P-value $<0.05$.

\section{RESULTS}

Weight and height measurements were taken on a total of 371 school children. Out of this number, 172 (46.4\%) were males while 199 (53.6\%) of them were females. The age of the studied population ranged from 3-14 years with mean of $8.4 \pm 2.8$. Height of the children on the other hand ranged from 0.9-1.64 meters with mean value of 1.26 \pm 0.15 and their weight ranged from $10-76 \mathrm{~kg}$ with mean value of $25.6 \pm 9.2$. Table 1 shows the mean height- for- age of the school children with their corresponding standard deviations and standard error of means. When the mean height values were plotted against age, a positive correlation was found. Mathematical modeling of height data demonstrated that the best-fitted regression model to describe the relationship between height and age is as shown in Figure 1. There is a positive polynomial correlation between age and height with a correlation of determination of $\mathrm{R}^{2}=0.9953(\mathrm{P}<0.05)$ in children in
Jos. The relationship is best described by the second order polynomial regression equation $\mathrm{y}=-0.0012 \mathrm{x}^{2}+0.0691 \mathrm{x}$ +0.7736 where $\mathrm{y}$ is the height in meters and $\mathrm{x}$ is the age in years. This means that age could predict the height of a child by 99.53 percent $\left(\mathrm{R}^{2}=0.9953\right)$ in 371 children in this study. After the mean height - for - age values of boys were compared with those of girls (Figure 2), it was found out that before 8 years of age, boys had higher values than girls but after that age, girls had significantly higher mean values $(\mathrm{P} \leq 0.05)$. This means that as from 8 years, girls grow faster than boys. When weight measurements were statistically analyzed, the mean weight - for - age values of the studied population were as shown in Table 2. A positive correlation was found between the mean weights values of the children were plotted against age. Numerical modeling of weight data established that the best-fitted regression model to explain the relationship between weight and age is as shown in Figure 3. This shows that there is a positive polynomial correlation between age and weight with a

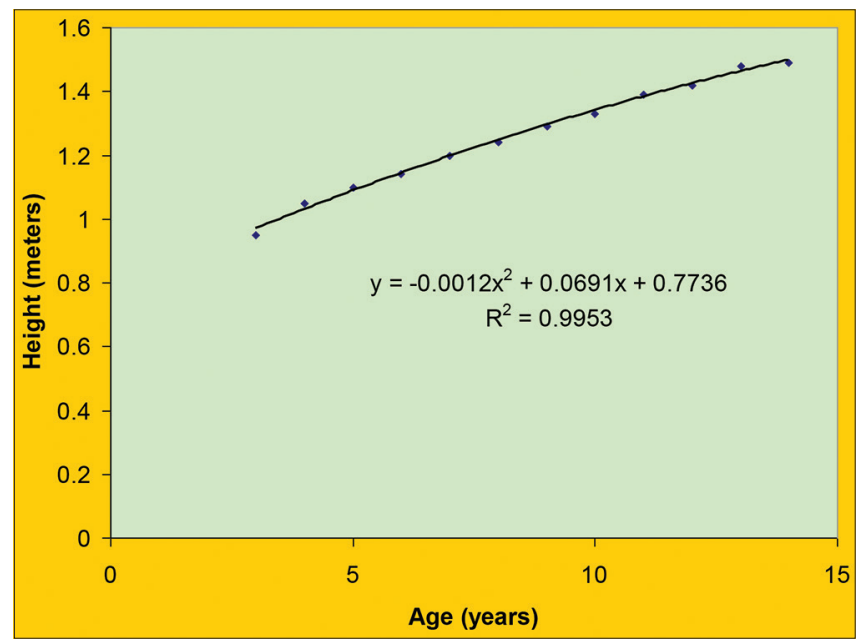

Figure 1: Correlation and regression equation of mean height in 371 children in Jos plotted against age in years

\begin{tabular}{|c|c|c|c|c|}
\hline Age (years) & $n$ & Mean Height (m) & SD & SEM \\
\hline 3 & 8 & 0.95 & 0.04 & 0.02 \\
\hline 4 & 24 & 1.05 & 0.04 & 0.09 \\
\hline 5 & 37 & 1.10 & 0.08 & 0.01 \\
\hline 6 & 33 & 1.14 & 0.09 & 0.02 \\
\hline 7 & 39 & 1.20 & 0.08 & 0.01 \\
\hline 8 & 44 & 1.24 & 0.09 & 0.01 \\
\hline 9 & 53 & 1.29 & 0.07 & 0.09 \\
\hline 10 & 43 & 1.33 & 0.09 & 0.01 \\
\hline 11 & 29 & 1.39 & 0.07 & 0.01 \\
\hline 12 & 30 & 1.42 & 0.08 & 0.01 \\
\hline 13 & 26 & 1.48 & 0.08 & 0.02 \\
\hline 14 & 5 & 1.49 & 0.12 & 0.05 \\
\hline TOTAL & 371 & & & \\
\hline
\end{tabular}

Number of examined persons ( $n$ ), standard deviation (SD) and standard error of mean (SEM) irrespective of gender 


\begin{tabular}{|c|c|c|c|c|}
\hline Age (years) & $n$ & Mean weight $(\mathbf{k g})$ & SD & SEM \\
\hline 3 & 8 & 13.4 & 1.9 & 0.7 \\
\hline 4 & 24 & 16.0 & 2.4 & 0.5 \\
\hline 5 & 37 & 17.4 & 2.8 & 0.5 \\
\hline 6 & 33 & 18.8 & 4.5 & 0.8 \\
\hline 7 & 39 & 21.1 & 4.0 & 0.6 \\
\hline 8 & 44 & 23.2 & 4.7 & 0.7 \\
\hline 9 & 53 & 26.5 & 5.1 & 0.7 \\
\hline 10 & 43 & 28.4 & 6.0 & 0.9 \\
\hline 11 & 29 & 31.8 & 4.7 & 0.9 \\
\hline 12 & 30 & 35.6 & 9.5 & 1.7 \\
\hline 13 & 26 & 40.3 & 8.6 & 1.7 \\
\hline 14 & 5 & 44.1 & 11.9 & 5.3 \\
\hline TOTAL & 371 & & & \\
\hline
\end{tabular}

Number of examined persons, standard deviation and standard error of mean irrespective of gender

correlation of determination of $\mathrm{R}^{2}=0.9986(\mathrm{P}<0.05)$ in children in Jos. The relationship is best described by the third order polynomial regression equation $\mathrm{y}=0.0092 \mathrm{x}^{3}$ $-0.0883 \mathrm{x}^{2}+2.0132 \mathrm{x}+8.2399$ where $\mathrm{y}$ is the weight in kilograms and $\mathrm{x}$ is the age in years. This means that age could predict the weight of a child by 99.86 percent $\left(\mathrm{R}^{2}=0.9986\right)$ in 371 children in this study. When the mean weight - for - age values of boys were compared with those of girls (Figure 4), it was found out that before 10 years of age, boys weigh higher than girls but after that age, girls weigh significantly higher than boys $(\mathrm{P} \leq 0.05)$.

When the mean values of weight were plotted against mean values of height, a positive correlation was found between these variables. Mathematical modeling of weight and height data demonstrated that the best-fitted regression model to describe the relationship between weight and height is as shown in Figure 5. Figure 5 clearly shows that there is a positive polynomial correlation between weight and height with a correlation of determination of $\mathrm{R}^{2}=0.9951(\mathrm{P}<0.05)$ in children in Jos. The relationship is best described by the third order polynomial regression equation $y=124.74 x^{3}-375.44 x^{2}+404.51 x-139.12$ where $\mathrm{y}$ is the weight in kilograms and $\mathrm{x}$ is the height in meters.

This means that height could predict the weight of children by 99.51 percent $\left(\mathrm{R}^{2}=0.9951\right)$ in 371 children in this study. Body mass index were calculated for each subject as ratio of body weight to body height and mean BMI for - age were obtained with standard deviation, standard errors of mean and $5^{\text {th }}, 15^{\text {th }}, 50^{\text {th }}, 85^{\text {th }}$ and $95^{\text {th }}$ centiles as shown in Tables 3 and 4 . Out of the 371 children studied, $14(3.8 \%)$ were found to be underweight, $302(81.4 \%)$ had healthy weight while $41(11 \%)$ were at risk of overweight and $14(3.8 \%)$ were overweight. When sex specific BMI - for - age percentiles were examined, it was found out that $4.5 \%$ of male children in the studied population were

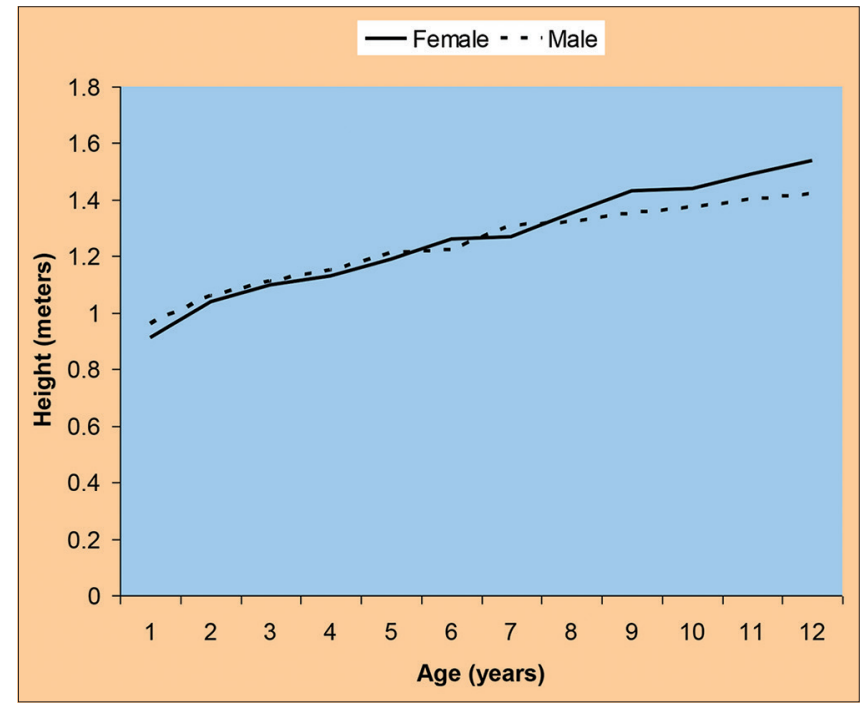

Figure 2: Comparison of Height - for - Age mean values for male and female children in Jos metropolis aged $3-14$ years

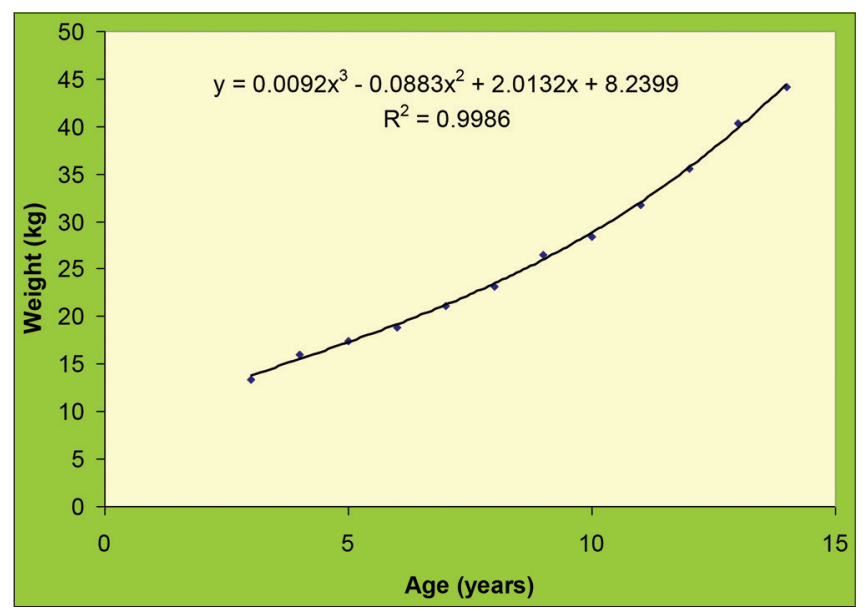

Figure 3: Correlation and regression equation of mean weight in 371 children in Jos plotted against age in years

underweight while $82.5 \%$ were healthy and $8 \%$ were at risk if overweight. Again, $5 \%$ of the male children were overweight. With respect to the female children, $79 \%$ had health weight, $8 \%$ underweight, while $11.6 \%$ were at risk of overweight and $4.7 \%$ were overweight. Furthermore, the body mass index of girls was found to significantly higher than those of boys at 12 and 13 years of age only.

\section{DISCUSSION}

This research report provides anthropometric reference data for children in Jos, North Central Nigeria. Out of the 371 children studied, 3.8\% were underweight, $81.4 \%$ had healthy weight while $11 \%$ were at risk of overweight and $3.8 \%$ were overweight. Similar findings were obtained in a study conducted in Kano, Nigeria, among 720 children and adolescents aged 6-18 years resident within the state. 


\begin{tabular}{|c|c|c|c|c|c|c|c|c|c|}
\hline \multirow[t]{2}{*}{ Age (years) } & \multirow[t]{2}{*}{$n$} & \multirow[t]{2}{*}{ Mean BMI } & \multirow[t]{2}{*}{ SD } & \multirow[t]{2}{*}{ SEM } & \multicolumn{5}{|c|}{ Centiles } \\
\hline & & & & & $5^{\text {th }}$ & $15^{\text {th }}$ & $50^{\text {th }}$ & $85^{\text {th }}$ & $95^{\text {th }}$ \\
\hline 3 & 8 & 14.9 & 1.6 & 0.6 & 13.0 & 13.2 & 14.3 & 17.0 & 17.0 \\
\hline 4 & 24 & 14.5 & 1.7 & 0.4 & 12.3 & 13.3 & 13.9 & 15.4 & 19.2 \\
\hline 5 & 37 & 14.3 & 1.3 & 0.2 & 11.8 & 12.9 & 14.1 & 15.8 & 16.5 \\
\hline 6 & 33 & 14.4 & 1.9 & 0.3 & 11.4 & 12.5 & 14.1 & 16.2 & 17.8 \\
\hline 7 & 39 & 14.5 & 1.9 & 0.3 & 10.2 & 12.9 & 14.3 & 16.5 & 18.0 \\
\hline 8 & 44 & 15.0 & 2.4 & 0.4 & 11.5 & 12.4 & 14.7 & 17.9 & 19.3 \\
\hline 9 & 53 & 15.9 & 2.1 & 0.3 & 12.9 & 14.1 & 15.9 & 17.8 & 20.5 \\
\hline 10 & 43 & 15.9 & 1.9 & 0.3 & 12.9 & 14.3 & 15.8 & 17.3 & 20.2 \\
\hline 11 & 29 & 16.6 & 1.9 & 0.4 & 12.5 & 14.8 & 16.6 & 18.2 & 20.6 \\
\hline 12 & 30 & 17.5 & 3.6 & 0.7 & 13.9 & 15.1 & 16.9 & 19.7 & 27.2 \\
\hline 13 & 26 & 18.3 & 2.8 & 0.6 & 13.6 & 16.0 & 17.8 & 21.9 & 25.3 \\
\hline 14 & 5 & 19.5 & 3.3 & 1.5 & 14.7 & 14.7 & 20.1 & 23.5 & 23.5 \\
\hline TOTAL & 371 & & & & & & & & \\
\hline
\end{tabular}

Mean, standard error of mean and selected percentiles irrespective of gender

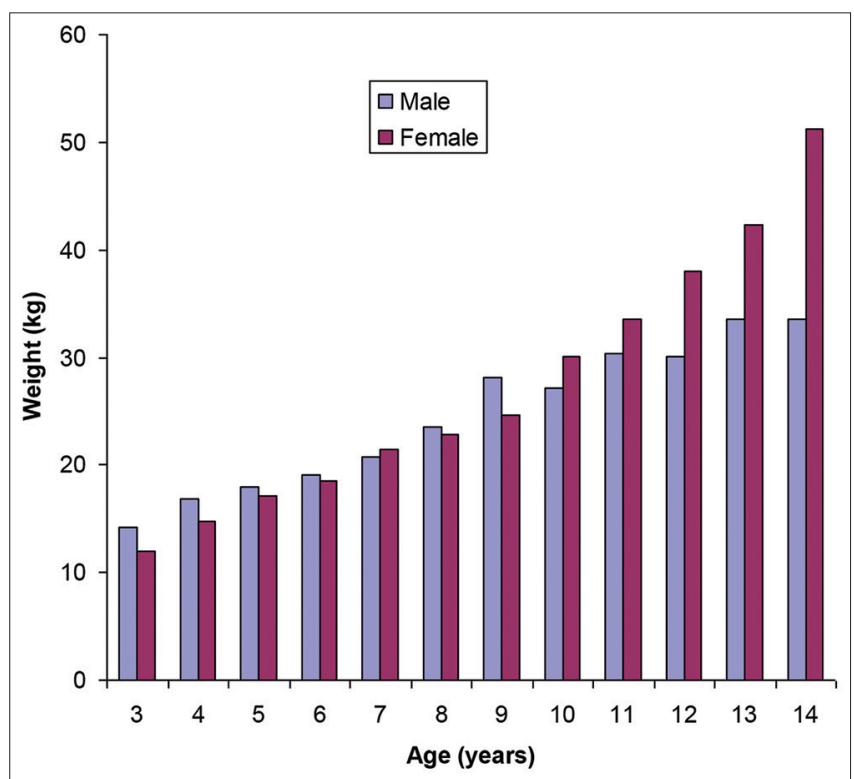

Figure 4: Shows bar chart comparing weight - for - age mean values for male and female children in Jos metropolis aged $3-14$ years

The results of the Kano study showed that the prevalence of obesity was $3.3 \%$ in the children aged 6-18 years ${ }^{9}$ while overweight prevalence was $8.9 \%$. A related study which was done in three centers (Lagos, Port Harcourt, Nsukka and $\mathrm{Aba}$ ) showed that $11.4 \%$ were overweight and $2.8 \%$ were obese. ${ }^{10}$ Conflicting evidence in the literature that are quite different from findings in the present study are those reported by. ${ }^{6,11-13} \mathrm{Abah}$ and his co-workers ${ }^{11}$ reported prevalence of $8.6 \%$ and $1 \%$ for overweight and obesity in that order in a study in Ekpoma, Edo State, Nigeria. Musa et al., ${ }^{6}$ reported a prevalence of $9.7 \%$ and $1.8 \%$ for overweight and obesity correspondingly among school children in Benue State, while Mustapha and Sanusi ${ }^{12}$ reported $5.8 \%$ and $1.1 \%$ for overweight and obesity respectively in a school based study in 2031 adolescents' population in Ondo. Yusuf et al., ${ }^{13}$ in a cross-sectional

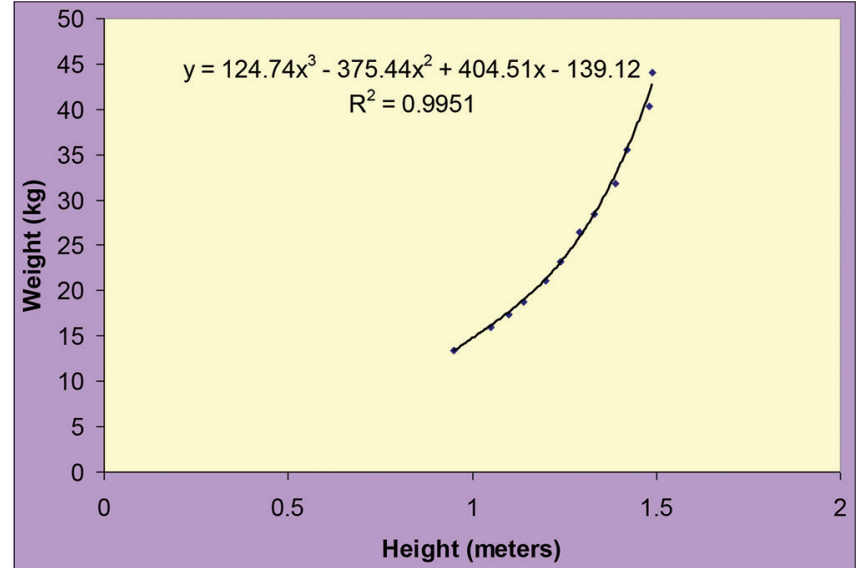

Figure 5: Correlation and regression equation of mean weight in 371 children in Jos plotted against height

study carried out in Kano among 718 school children reported obesity prevalence of $0.84 \%$ and prevalence of overweight as $1.98 \%$. The differences in the values reported by previous investigators and those of the present study is likely to be due to the fact that BMI was interpreted using weight status categories instead of using BMI-age-specific percentiles as it was done in the present study.

Paediatricians concerned with the care and development of children as well as with prevention and treatment of children diseases can keep as part of their diagnostic tools, charts and nomograms, such as the ones provided above, and keep some important prediction formulae in their head. With the help of a small pocket calculator they can arrive at highly scientific management of their patients, even in areas far removed from sophisticated clinical gadgetry. In situations where weight is not known because of failure of appropriate technology such as lack of electricity or no weight machine, propounded prediction formula for weight derived from age can be 


\begin{tabular}{|c|c|c|c|c|c|c|c|c|c|}
\hline \multirow[t]{2}{*}{ Age \& Sex } & \multirow[t]{2}{*}{$n$} & \multirow[t]{2}{*}{ Mean BMI } & \multirow[t]{2}{*}{ SD } & \multirow[t]{2}{*}{ SEM } & \multicolumn{5}{|c|}{ Centiles } \\
\hline & & & & & $5^{\text {th }}$ & $15^{\text {th }}$ & $50^{\text {th }}$ & $85^{\text {th }}$ & $95^{\text {th }}$ \\
\hline \multicolumn{10}{|l|}{ Males } \\
\hline 3 years & 5 & 15.3 & 1.6 & 0.7 & 13.3 & 13.5 & 14.4 & 18.5 & 19.2 \\
\hline 4 years & 14 & 15.0 & 2.0 & 0.5 & 11.8 & 12.3 & 14.3 & 16.0 & 17.1 \\
\hline 5 years & 13 & 14.5 & 1.6 & 0.4 & 12.5 & 12.6 & 14.2 & 15.9 & 16.5 \\
\hline 6 years & 14 & 14.3 & 1.2 & 0.3 & 9.6 & 12.5 & 14.0 & 16.1 & 16.6 \\
\hline 7 years & 20 & 14.0 & 1.9 & 0.4 & 7.9 & 13.7 & 15.7 & 18.1 & 20.1 \\
\hline 8 years & 20 & 15.6 & 2.7 & 0.6 & 13.2 & 13.9 & 16.5 & 18.5 & 21.1 \\
\hline 9 years & 29 & 16.0 & 2.1 & 0.4 & 12.5 & 14.1 & 15.6 & 16.7 & 18.6 \\
\hline 10 years & 24 & 15.5 & 1.5 & 0.3 & 12.1 & 15.1 & 16.7 & 17.9 & 20.9 \\
\hline 11 years & 16 & 16.6 & 1.8 & 0.5 & 13.2 & 14.2 & 15.9 & 18.0 & 18.9 \\
\hline 12 years & 9 & 16.0 & 1.5 & 0.5 & 13.3 & 13.3 & 16.7 & 18.1 & 18.1 \\
\hline 13 years & 6 & 16.0 & 1.8 & 0.7 & 13.3 & 13.3 & 16.7 & 18.1 & 18.1 \\
\hline 14 years & 2 & 16.3 & 2.3 & 1.6 & 14.7 & 14.7 & 16.3 & 17.9 & 17.9 \\
\hline \multicolumn{10}{|l|}{ Females } \\
\hline 3 years & 3 & 14.4 & 1.9 & 1 & 13.0 & 13.0 & 13.6 & 16.5 & 16.5 \\
\hline 4 years & 10 & 13.8 & 0.9 & 0.3 & 12.0 & 12.6 & 13.8 & 15.0 & 15.2 \\
\hline 5 years & 24 & 14.1 & 1.2 & 0.2 & 11.9 & 12.9 & 14.1 & 15.4 & 16.3 \\
\hline 6 years & 19 & 14.4 & 2.3 & 0.5 & 10.6 & 12.0 & 14.1 & 16.6 & 20.2 \\
\hline 7 years & 19 & 15.0 & 1.9 & 0.4 & 12.0 & 13.0 & 14.6 & 17.5 & 19.7 \\
\hline 8 years & 24 & 14.5 & 2.0 & 0.4 & 11.5 & 12.4 & 14.2 & 17.0 & 19.3 \\
\hline 9 years & 24 & 15.3 & 2.1 & 0.4 & 11.5 & 14.1 & 14.8 & 16.5 & 21.8 \\
\hline 10 years & 19 & 16.4 & 2.1 & 0.5 & 13.9 & 14.7 & 15.9 & 17.8 & 22.9 \\
\hline 11 years & 13 & 16.6 & 2.1 & 0.6 & 13.0 & 14.7 & 16.4 & 19.8 & 20.3 \\
\hline 12 years & 21 & 18.2 & 4.0 & 0.9 & 14.5 & 14.9 & 17.4 & 20.7 & 32.6 \\
\hline 13 years & 20 & 18.9 & 2.7 & 0.6 & 15.2 & 16.5 & 18.1 & 22.6 & 26.5 \\
\hline 14 years & 3 & 21.6 & 1.7 & 1.0 & 20.1 & 20.1 & 21.2 & 23.5 & 23.5 \\
\hline TOTAL & 371 & & & & & & & & \\
\hline
\end{tabular}

utilized. Furthermore, in mass therapeutic clinic situations, as in mobile clinics, when age is unknown (this is often the case in some rural communities), weight or height may be recorded and age predicted from the propounded prediction formula. Similarly, BMI age specific percentile chart can be used to determine the nutritional status of a child at any given age. In conclusion, the values presented in this study are the weight, height and BMI age and sex specific values for contemporary Nigerian children in Jos, North Central Nigeria. Regression analysis have allowed for the calculation of prediction formulae. They can be utilized when facilities for measurement are non-existent in critical and other clinical situations.

\section{ACKNOWLEDGMENT}

The authors appreciate staff and pupils of ECWA Private School Anglo Jos for their whole hearted support for this study.

\section{REFERENCE}

1. Diejomaoh FM and Faal MK. The heights and weights of secondary school girls in Benin City, Nigeria. Tropical and Geographical Medicine. 1982; 34(4):359-363.

2. Ayoola O, Ebersole K, Omotade OO, Tayo BO, Brieger WR,
Salami K, et al. Relative height and weight among children and adolescents of rural southwestern Nigeria. Annals of Human Biology. 2009; 36(4):388-399.

https://doi.org/10.1080/03014460902835606

3. Fetuga MB, Ogunlesi TA, Adekanmbi AF and Alabi AD. Growth pattern of schoolchildren in Sagamu, Nigeria using the CDC standards and 2007 WHO standards. Indian Pediatrics. 2011; 48(7):523-528.

https://doi.org/10.1007/s13312-011-0094-x

4. Adesina AF, Peterside $O$, Anochie I and Akani NA. Weight status of adolescents in secondary schools in Port Harcourt using Body Mass Index (BMI). Italian Journal of Pediatrics. 2012; 38:31. https://doi.org/10.1186/1824-7288-38-31

5. Ansa VO, Odigwe $\mathrm{CO}$ and Anah MU. Profile of body mass index and obesity in Nigerian children and adolescents. Nigerian Journal of Medicine. 2001;10(2):78-80.

6. Musa DI, Toriola AL, Monyeki MA and Lawal B. Prevalence of childhood and adolescent overweight and obesity in Benue State, Nigeria. Tropical Medicine and International Health. 2012;17.11:1369-1375.

https://doi.org/10.1111/j.1365-3156.2012.03083.x

7. Snedecor GW and Cochran WG. Statistical methods. $6^{\text {th }}$ Edition, The lowa State University Press, Ames. 1967

8. Opara DC, Ikpeme EE and Ekanem. Prevalence of Stunting, Underweight and Obesity in School Aged Children in Uyo, Nigeria. Parkistan Journal of Nutrition. 2010; 9(5). 459-466. https://doi.org/10.3923/pjn.2010.459.466

9. Ismail MK, Umar IU, Garba DG and Muutassim I. Prevalence of Childhood and Adolescent Overweight and Obesity in Kano State, Nigeria. EC Paediatrics. 2018; 7.4 231-238. 
10. Ene-Obong $\mathrm{H}$, Ibeanu $\mathrm{V}$, Onuoha $\mathrm{N}$ and Ejekwu A. Prevalence of overweight, obesity, and thinness among urban school-aged children and adolescents in southern Nigeria. Food and Nutrition Bulletin. 2012; 33.4: 242 - 250.

https://doi.org/10.1177/156482651203300404

11. Abah SO, Aigbiremolen AO, Duru CB, Awunor NS, Asogun $A D$, Enahoro FO, et al. Prevalence of obesity and overweight in private and public secondary school in peri-urban Nigerian town. Journal of Biology, Agriculture and Healthcare. 2012; 11: 2224-3208.

12. Mustapha RA and Sanusi RA. Overweight and obesity among in-school adolescents in Ondo State, Southwest Nigeria. African Journal of Biomedical Research. 2013; 205 -210.

13. Yusuf SM, Mijinyawa MS, Musa BM, Gezawa ID and Uloko AE. Overweight and Obesity among Adolescents in Kano, Nigeria. Journal of Metabolic Syndrome. 2013; 2:126.

\section{Author's Contributions:}

OM-Concept and design of the study, prepared first draft of manuscript; FS- interpreted the results; reviewed the literature and manuscript preparation;

JN- Concept coordination, review of literature and manuscript preparation; EM- statistically analyzed and interpreted, preparation of manuscript and revision of

the manuscript.

Work attributed to:

Faculty of Basic Medical Sciences, University of Jos.

Orcid ID:

Dr. Omolara Mosugu- (i) http://orcid.org/0000-0002-5481-2034

Dr. Francis Shinku- (iD http://orcid.org/0000-0001-7080-9276

Dr. Jacob Nyam- (i) http://orcid.org/0000-0002-7399-5745

Professor Emmanuel Mador- (1) http://orcid.org/0000-0002-2500-0416

Source of Funding: Nil, Conflict of Interest: None. 